\title{
EDUCATION, LIBRARIES, AND THE INTERNET: A SELECT ERIC BIBLIOGRAPHY
}

\author{
Submitted by \\ Nancy R. Preston
}

Bailey, Charles W., Jr. (1992, March). Network-Based Electronic Serials. Information Technology and Libraries, 11(1), 2935. (Available UMI). EJ 444777.

Discusses electronic serials that are available on noncommercial international computer networks suchas BITNET and the Internet. Issues affecting libraries are discussed, including access and ownership; computerconferences are considered; examples of electronic newsletters and electronic journals are described; and the possible future of electronic serials is examined.

Brunell, David H. (1991). Internetworking Services and the Electronic Library. Journal of Library Administration, 15(3-4), 21-36. EJ 446236.

Discusses management issues that librarians face in offering public access to library resources through internetworking services, e.g., local area networks, campus networks, or the Internet. It is concluded that interface problems and lack of an effective technical support structure make access to library information on Internet more of an experiment than an ongoing service at this time.

Clement, John. (1992, May-June). K-12 Networking: Constructing the K-12 Collaboratory on the NREN. EDUCOM Review, 27(3), 18-20. (Available UMI). EJ 447485.

Argues that the real worth of wide-area computer-mediated communications networks in supporting reform and improvement in $\mathrm{K}-12$ education is the opportunity to develop collaborative projects that link educators and students to provide meaningful learning experiences connected to the curriculum, and that such projects are essential to make NREN an empowering tool for educational reform on a national scale.

Doyle, Patrick. (1992, May). K-12: Linking to the National Networks. Computers inLibraries, 12(5),61-62. (Available UMI). EJ 446262.

Discusses the possibilities of linking elementary and secondary schools to the Internet. The use of technology to improve education by gaining access to greater amounts of information is described; costs associated with joining the Internet are considered; and possible sources of funding for joining are suggested.
Ladner, Sharyn, and Tillman, Hope N. (1992). How Special Librarians Really U se the Internet: Summary of Findings and Implications for the Library of the Future. Available through the Internet, through FTP, at host hydra.uwo.ca, directory LibSoft, and filename SPEC_Libs.txt. ED 345751.

Offers the results of a 1991 electronic survey of special librarians to determine which computer conferences they subscribed to; the length of time they had been using BITNET or the Internet; and their training. In addition, respondents ranked the following uses according to importance: electronic mail and computer forums, remote database searching, file transfer and data exchange, and research and publication on the Internet.

McClure, Charles. (1992, April). A User Perspective on Developing Internet Services. Computers in Libraries, 12(4), 53-55. (Available UMI). EJ 444824.

Discusses the development of networked information services from a user's perspective. Topics discussed include user education; the issue of access to, versus retrieval of, information; the role of the library, including education and training, bibliographic control, and electronic information services; and training and education for librarians.

McClure, Charles R. (1992, Spring). From the Editor: The High Performance Computing Act of 1991. Electronic Networking: Research, Applications and Policy, 2(1), 2-9. EJ 446177.

Discusses issues related to the High Performance Computing and Communication program and National Research and Education Network (NREN) established by the High Performance Computing Act of 1991, including program management, specific program development, affecting policy decisions, access to the NREN, the Department of Education role, and dissemination of government information. A copy of the law is appended.

Peters, Paul Evan. (1992, April). Networked Information Resources and Services: Next Steps. Computers in Libraries, 12(4), 46-53. (Available UMI). EJ 444823.

Argues that advanced networks, particularly BITNET, NSFNet, Internet, and NREN can simplify global networking as well as library functions and interfaces; provide easier and more cost-effective connection of the research and education communities; and transport very large amounts of information. 
Roberts, Michael M. (1992, May-June). Networking: Testimony to the United States House of Representatives Committee on Science, Space and Technology Subcommittee on Science. EDUCOM Review, 27(3), 14-17. (Available UMI). EJ 447484.

Tes timony to a congressional subcommittee stresses the importance of national broadband communications networks such as NREN and NSFNet to the educational community. Approval for a proposed private sector infrastructure for the NREN is discussed.

Roberts, Michael M. (1992, May). A Political Perspective on the Internet and NREN. Computers in Libraries, 12(5), 58-61. (Available UMI). EJ 446261.

Provides political background on the National Research and Education Network (NREN). The growth of computer information networks is discussed, including the Internet and NSFNet; the legislative process involved with creating the NREN is explained; and the future prospects for a National Information Infrastructure are (NII) discussed.

Saunders, Laverna M. (1992, Spring). The Virtual Library Today. Library Administration and Management, 6(2), 66-70. (Available UMI). EJ 444781.

Discusses the concept of a virtual library. Current systems are described, as well as pilot projects; administrative concerns are addressed, including cooperative collection development and networking; work of the Coalition for Networked Information is discussed; and the National Research and Education Network is described.

\section{How to Oblain Materials Cited in this Bibliography:}

Citations with ED numbers are documents from Resources in Education. They can be read at a library with an ERIC microfiche collection or ordered, in paper or microfiche copy, from the ERIC Document Reproduction Service, 7420 Fullerton Road, Suite 110, Springfield, VA 22153-2852. Phone: 1-800443-ERIC or 703-440-1400.

Citations with EJ numbers are journal articles from Current Index to Journals in Education. They can be obtained from a college, university, or public library, borrowed through interlibrary loan, or, if so indicated, ordered from: UMI Article Clearinghouse, 300 N. Zeeb Road, Ann Arbor, MI 48106. Phone: 1-800-521-0600.

Nancy R. Preston. Assistant Director at the ERIC Clearinghouse on Information Resources, 030 Huntington Hall, Syracuse University, Syracuse, NY 13244-2340; (315) 443-3640; npreston@suvm.syr.edu. 